\title{
An ARTMAP-incorporated Multi-Agent System for Building Intelligent Heat Management
}

\author{
Maizura Mokhtar, Member, IEEE, Xiongwei Liu Member, IEEE
}

\begin{abstract}
This paper presents an ARTMAP-incorporated multi-agent system (MAS) for building heat management, which aims to maintain the desired space temperature defined by the building occupants (thermal comfort management) and improve energy efficiency by intelligently controlling the energy flow and usage in the building (building energy control). Existing MAS typically uses rule-based approaches to describe the behaviours and the processes of its agents, and the rules are fixed. The incorporation of artificial neural network (ANN) techniques to the agents can provide for the required online learning and adaptation capabilities. A three-layer MAS is proposed for building heat management and ARTMAP is incorporated into the agents so as to the facilitate online learning and adaptation capabilities. Simulation results demonstrate that ARTMAPincorporated MAS provides better (automated) energy control and thermal comfort management for a building environment in comparison to its existing rule-based MAS approach.
\end{abstract}

Index Terms-Building Management System, Intelligent Energy Management System, Multi-Agent System, Neural Network.

\section{INTRODUCTION}

Energy demand on space heating in the UK accounts for approximately $50 \%$ of the total energy demand from building environment. Saving a fraction of the energy used for space heating will make a significant difference on reducing fossil fuel consumption, securing energy supply and combating greenhouse gas emissions.

There are many different ways to reduce energy consumption for space heating in a building environment, for example through both technology innovation and behaviour change. Technology innovation, such as intelligent energy management system (IEMS), will improve energy efficiency by reducing energy waste and facilitating behaviour change. "Intelligence" of an IEMS allows for the prediction of energy usage and this predictive information can help IEMS achieve these objectives.

Comfort standards in a building environment are generally determined by three fundamental factors: thermal (temperature) comfort, visual (lighting) comfort and indoor air quality. Among these three factors, thermal comfort has the number one impact on energy consumption. In this paper, we will only address the thermal comfort.

Nowadays, building infrastructure are improved to help promote energy saving, but inefficient energy management of its heating system may lead to unnecessary waste. In a commercial building environment in winter, such as in the

This work is part funded by BAE Systems UK.

M. Mokhtar and X. Liu are with the School of Computing, Engineering and Physical Sciences, University of Central Lancashire, Preston, PR1 2HE, UK (email: \{MMokhtar,XLiu9\}@uclan.ac.uk)
UK, room temperatures are generally kept at a comfort level of approximately $22^{\circ} \mathrm{C}$, whether they are occupied or not, and very often the windows are open because some of the occupants may feel hot. This results in unnecessary energy waste. IEMS can help address this issue by:

1) addressing the unnecessary heating of rooms without occupation,

2) profiling the movements of its occupier, and

3) adapting the comfort standard to the occupants preferences and movements.

Because of the thermal resistivity of a building, these three steps are closely related to each other.

Furthermore, energy saving and thermal comfort satisfaction are often in conflict to each other. For example, high thermal comfort satisfaction generally results in high energy consumption (low energy saving). Therefore, in order to reduce energy consumption for space heating, satisfaction of occupant thermal comfort may have to be compromised, by reducing the comfort level down to a point where the occupier begin to recognise the difference.

One approach that can provide for this compromise is to introduce an intelligent energy management system (IEMS) for the building heat management. The IEMS will be capable of predicting and profiling energy usage of the building according to, both:

1) the minimisation of the energy consumption and energy cost, and

2) the maintenance of the thermal comfort at an acceptable level.

This is a multi-objective control optimisation problem, particularly for large buildings like hotels, office buildings, public and commercial building environment.

This paper presents an IEMS that can provide for the building energy control and thermal comfort management to meet the objectives of achieving energy saving and thermal comfort satisfaction. The paper is divided into six sections. Section II overviews the existing techniques used for building energy control and thermal comfort management. Section III describes the proposed techniques. Section IV introduces the case study used to test the proposed technique, and Sec. V presents the results. Section VI concludes the paper.

\section{Building ENERgy Control ANd THERMAL COMFORT MANAGEMENT}

Different approaches have been proposed to minimise energy consumption and energy cost, and at the same time to 
achieve an acceptable thermal comfort in a building environment. Energy control and thermal comfort management in a building environment (or BEC-TCM) is a time-variant dynamic system with both logic on/off states and continuous (real number) states. Dounis [1] classified energy control and thermal comfort management as to either use conventional controllers (such as PID controller and adaptive controller), computational intelligence techniques (such as ANN, genetic algorithms, fuzzy logic, and their combinations), and/or multiagent system (MAS).

The requirement for a comprehensive mathematical model has limited the application of conventional control systems; therefore the use of computational intelligence techniques and MAS-approaches have gained interest in the last decade. Furthermore, the energy control and thermal comfort management processing uses both logic control and continuous states (process) with partial differential equations or differential equations; which, can be addressed using the computational intelligence techniques and MAS-approaches. Below are some examples of BEC-TCM that uses these approaches.

\section{A. Fuzzy-based Thermal Comfort Management}

Thermal comfort is referred to as the state of mind that expresses satisfaction with the temperature in a building environment. The definition of thermal comfort depends on the psycho-synthesis of the occupants in a building environment, and fundamentally is a fuzzy concept, which differs from people to people and depends on the type of activities they are engaged in [1], [3]. Because of this, fuzzy logic (human approximate classification and reasoning) have found broad applications in both logic (on/off) states and continuous state (process) control in building environment [1] - [5].

\section{B. ANN-based Thermal Comfort Management}

Liang [6] developed a thermal comfort controller for building environment based ANN. In the thermal comfort controller, predictive mean vote (PMV) [7], [8] is adopted as the control objective. Liang has developed a back-propagation based ANN that is used for the PMV calculation. Simulation demonstrated that the thermal comfort controller can maintain the thermal comfort level within the desired range. However, due to the slow convergence of back-propagation, the controller may not be a feasible solution for large building environment. And furthermore, ANN based control algorithms usually use offline adaption, which limits its capacity to adapt the comfort standard to the occupants preferences in real time.

\section{Neuro-fuzzy Thermal Comfort Management}

Neuro-fuzzy systems combine ANN and fuzzy techniques. The neuro-fuzzy control technique was developed by Yamaha et. al. [9] to predict weather parameters and the number of occupants in a building. This predictive information are then used to profile the energy flow for the building in order to minimise energy consumption and to maintain thermal comfort at an acceptable level.

\section{Multi-Agent Systems (MAS) approach}

A multi-agent system (MAS) consists of two or more intelligent agents in an environment. Each agent has its own functions or goals, and interacts with each other in a peerto-peer (decentralised or distributive) manner so as to achieve its goals or objectives. Multi-agent systems are particularly favoured by researchers in building energy control and thermal comfort management because of their distinctive advantages, including distributive or decentralised control, modular structure and openness, self-capacities, self-organisation and highlevel transparency. For example, each room in the building will have its own individual room temperature and thermal comfort control that is independent of the boiler control system. Mutual agreement and decision making are achieved through communication between the agents in the building.

It is better to use a group of distributed controllers (intelligent agents) rather than a single one. The number of the distributed agents depends very much on the size and functions of the building environment [11] - [16]. A large commercial building may have hundreds even thousands of distributed agents for the building energy control and thermal comfort management.

MAS alone has a low level of on-line learning and adaptation capabilities. Recently, incorporation of ANN and/or fuzzy techniques into the agent-based systems have been discussed with the goal of improving online learning and adaptation capabilities of MAS and other performance improvement, as indicated in [14] - [16].

This paper incorporates ARTMAP, a supervised ANN, to the MAS for building energy control and thermal comfort management.

\section{MARTMAP-MAS BUILDING ENERGY CONTROL \& THERMAL COMFORT MANAGEMENT}

\section{A. ARTMAP}

ARTMAP or Adaptive Resonance Theory (ART) MAP or Predictive ART, developed by Carpenter et. al. [18], is a supervised artificial neural network (ANN) algorithm and inspired by how human process memory. ARTMAP is able to learn new information without necessarily forgetting previously learned information [17], [18]. As illustrated in Fig. 1, ARTMAP deals with the stability and plasticity issues by combining two adaptive resonance theory (ART) networks, i.e. ART a and ART $\mathrm{b}$, which have the ability to establish memory (the input-to-output correlation) within the networks. A memory is created through the interconnection that transfers short term memory (STM) to and from long term memory (LTM) within each ART network [17], [18]. ARTMAP performs both prediction and classification, and is an ideal tool for online learning and adaptation of an agent.

As described in [17], [18], ARTMAP works by classifying and categorising the inputs presented to the network (at ART a) according to the desired categories (supervisory input) presented at ART b. During supervised learning, ART a receives the inputs that needed to be classify, whilst ART $b$ indicates how the provided inputs should be classify. As illustrated in Fig. 1, the two ARTs are linked by an associative memory. 


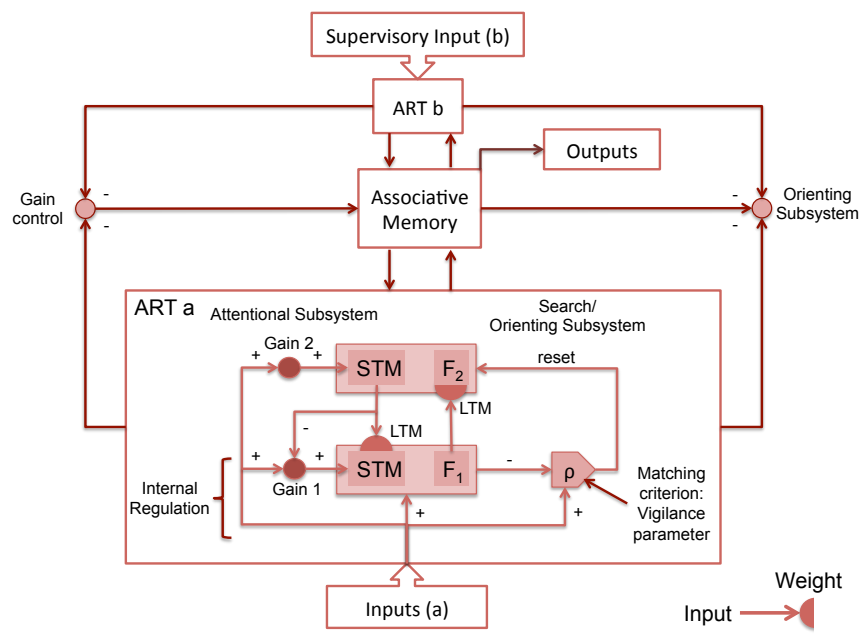

Fig. 1. ARTMAP structure. ARTMAP works by classifying and categorising the inputs presented to the network at ART a according to the supervisory inputs (desired categories) presented at ART b.

The associative memory consists of an associative map and a controller called the map field that prevent proliferation of categories established within the ART a network [18]. The associative map does not directly associates inputs presented to ART a and ART $b$, but instead creates the association between the category activation produced by ART a and ART $b$ given its input values [18]. The map field uses a minimax learning rule that automatically links predictive success (the category activation produced by ART a) that matches the category activation produced by ART $b$. The learning rule is executed on a trial-by-trial basis, by increasing the vigilance parameter of ART a $\left(\rho_{a}\right)$ by the minimum amount needed to make the corrective predictive error at ART b [18]. The smaller the $\rho_{a}$ value, the bigger the size of the category. This process is called match tracking. Match tracking sacrifices generalisation in order to ensure minimal predictive error [18].

If the predictive error persist, a new category is created within ART a, which will correlates the new input patterns presented to ART a to the input (category) information presented to ART b.

This architecture helps the ARTMAP learn new data without forgetting its previously learnt information, as well as providing the ability to infer the adaptive output response for a given system based on this newly acquired memory. After learning is completed, no supervisory inputs are presented to ART b, and ART a alone is responsible for providing the required output response for the system [17], [18].

\section{B. IARTMAP - The User-friendly ARTMAP}

Like all ANN approaches, ARTMAP employs a similar black-box mechanism to its input-to-output learning and mapping functionalities. When learning is instigated, the ARTMAP will learn the input-to-output mapping of the desired outputs for a given inputs presented at ART a and ART $b$ respectively by its supervisor. Because of this, we add an additional component to the ARTMAP, called the Supervisor component (as illustrated in Fig. 2) to allow for seamless interaction between the ARTMAP and its users, in order to ensure transparency.

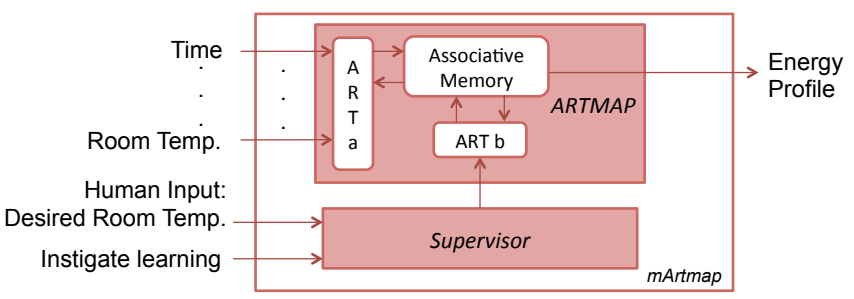

Fig. 2. The modified ARTMAP (mARTMAP). mARTMAP allows for the seamless interaction between the users of the intelligent energy management system (IEMS) and the ARTMAP.

1) Supervisor: When the users present new supervisory inputs to the ARTMAP ${ }^{1}$, the Supervisor takes in this input information, presents this input to ART b (Fig. 2) and instigates the learning of the new input-to-output mapping for the ARTMAP (Learn $=1)$. The presented supervisory input corresponds to the input information provided to ART a. Supervisor will monitor the input and output provided by the ARTMAP and indicate when to stop the learning process $($ Learn $=0)$, to stop when the Supervisor detects that ARTMAP has adapted its network with the new input-tooutput relations. This allows seamless adaptation (or learning) of the network (for the ARTMAP) without any re-coding of the infrastructure, as well as promoting transparency.

2) Variable $\rho$ : Two different values of the vigilance parameter $\rho$ is used. $\rho=0.9$ is used when Learn $=1$; and $\rho=0.75$ otherwise.

Higher value of $\rho$ allows the increase in specification towards the most relevant output when the mARTMAP is in its learning phase. Smaller value of $\rho$ allows for greater generalisation of the network towards the best match output, when not in the learning phase.

\section{MAS Structure}

The proposed MAS is structured with three distinctive layers (Fig. 3):

1) User Layer: User layer consists of User Agents. A User Agent is designed to provide for the thermal comfort management of a room with functions similar to the three agents presented by Davidson et. al., 2000 [11]. The main difference between our work and that presented by Davidson et. al [12], is that each User Agent is incorporated with two mARTMAPs rather than the three separate agents. The two mARTMAPs are used (each) (i) to control how much heat is to be provided to the room, and (ii) to learn the users' thermal preferences based on the (current) environmental conditions and users' inputs and behaviours (Sec. IV-B2).

2) Mediatory Layer: Mediatory layer consists of a Mediator Agent that is responsible in decision aggregation and configuration for the MAS (similar to that presented in Qiao et. al. [14]).

3) Source Layer: Source layer consists of Source Agents. A Source Agent is responsible for the building energy control by managing how much energy is to be provided to the building

\footnotetext{
${ }^{1}$ The ARTMAP functionalities are provided by the Matlab codes produced by A. Garrett [10].
} 


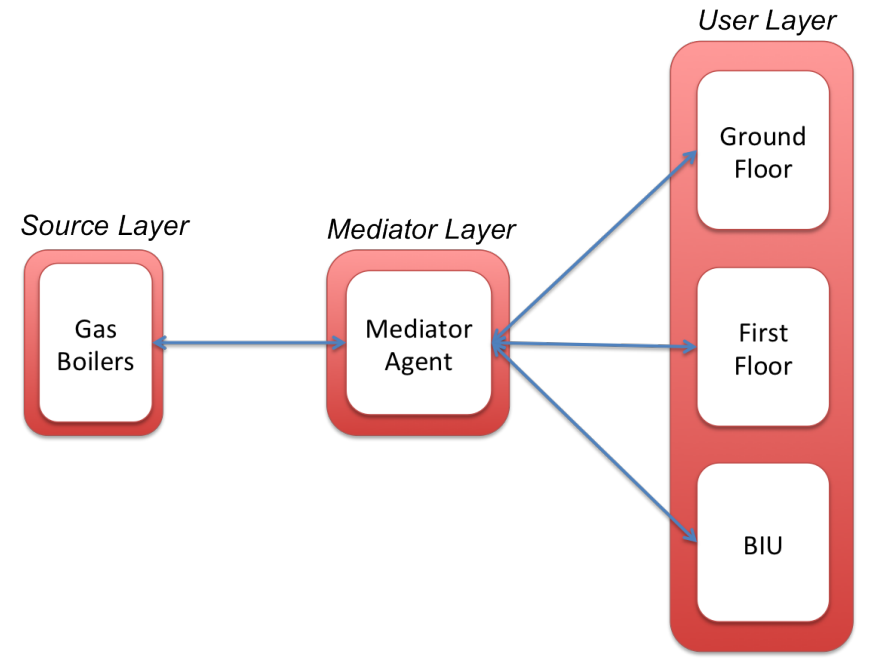

Fig. 3. The 3-layer multi-agent system for UCLan WestLakes SLB IEMS.

based on the demand information provided by the User Agents. The Source Agent consists of three mARTMAPs: (i) to control how much heat is provided to the building, (ii) to learn of the overall building thermal preferences, and (iii) to learn of the building heat demand, based on the (current) environmental conditions and users' inputs and behaviours described by the User Agents.

\section{Intelligent Heat Management System (IHMS)}

As described in previous sections, building thermal comfort management aims to increase efficiency of the heat management system of the building, whilst maintaining the required comfort preferences of the occupants. This is achieved by creating an intelligent heat management system (IHMS) based on ARTMAP-incorporated MAS approach. mARTMAPs are incorporated to the User Agents and the Source Agents, so as to, as previously indicated to (i) predict the heat demand for the building, (ii) provide the required heat based on the predicted demand, and (iii) learn and adapt its functionalities seamlessly based on the new demand characteristics provided by the occupants.

\section{EXPERIMENT: IHMS FOR UCLAN WESTLAKES SLB}

A case study on UCLan WestLakes Samuel Lindow Building (SLB) [19] is used to test the capabilities and performance of the IHMS incorporated with the mARTMAP-MAS, in comparison to its existing building management system (BMS). For this purpose, a building environment simulation model of SLB is created. SLB is a three storey building consisting of a lecture theatre, offices, computer labs and an open space.

Since we are concentrating predominantly on the heat management, the building simulation model (based on Matlab thermal model [20]) describes for all rooms in the building:

1) the heat transfer from the hot water (heat source - water is heated to a set temperature by the boilers) to the radiator installed in the room,

2) from the radiator to the air in the room, and
3) the heat losses through the walls and windows due to the temperature difference between the space in the room and the outside environment.

In order to simplify the simulation model, it is assumed that there is no heat transfer between the rooms. The building environment simulation model is developed using MATLAB ${ }^{\circledR}$ and Simulink ${ }^{\circledR}$.

\section{A. Modelling on SLB Existing BMS}

The SLB existing BMS divides the building into three zones. Each zone is assigned with a User Agent controlling the temperature of the hot water flowing to its specific zone. The three zones are: (i) the Lecture Theater and the back rooms of the ground floor, (ii) the Business Incubation Unit (BIU) that consists of a large open office space and three smaller offices and (iii) the first and second floors. In our SLB's building simulation model, the zone temperature is the average temperature of all the rooms in the particular zone ${ }^{2}$.

The User Agents are incorporated with a set of rules (rulebased method) to ensure that the building is maintained within the desired temperature. The rules are:

If ( zone temperature $<$ desired temperature )

Then hot water temperature $\approx \max \left(80^{\circ} \mathrm{C}\right)$;

Else hot water temperature is decreased and

maintained at the decreased temperature until

zone temperature $=\left(\right.$ desired temperature $\left.-2^{\circ} \mathrm{C}\right)$;

The hot water temperature to a zone is decreased by mixing hot water from the boiler with the return water from the heaters in the zone. The desired temperature of the zone are:

\section{If ( during the weekdays )}

Then desired temperature $\approx 23^{\circ} \mathrm{C}$;

Else desired temperature $\approx 10^{\circ} \mathrm{C}$;

The Source Agent states that:

If during the weekdays and between 02:00 to $21: 00 \mathrm{hr}$

Then boiler is switched on and

hot water temperature $\approx 80^{\circ} \mathrm{C}$;

Else boiler is switched off and the water temperature

from the boiler is decreased accordingly;

There are no mediator layer in the existing BMS.

\section{B. MARTMAP-MAS approach}

Fig. 3 illustrates the proposed mARTMAP-MAS IHMS.

1) Mediator Agent: The Mediator Agent is responsible for acknowledging, accepting and deleting of the User Agents and Source Agents within the MAS.

As indicated in Section IV-A, there are three User Agents and one Source Agent in the SLB's MAS structure. Therefore, the Mediator Agent will be responsible for acknowledging the three User Agents and inform the Source Agent that there are three zones (each indicated by its respective User Agent) requiring heat. The Mediator Agent will also provide the Source Agent with each User Agent's room/zone heat demand information and energy profile.

\footnotetext{
${ }^{2}$ In the actual building, there are only one temperature sensor per zone
} 
2) User Agent: The User Agent's mARTMAPs aim to maintain the desired temperature setting (previously defined by the occupants) by correlating and categorising the inputs presented to the mARTMAPs, and indicates if hot water flow (heat source) is required by the room (mARTMAP1) and the best effective desired temperature for the room $\left(\right.$ mARTMAP2 $\left.{ }^{3}\right)$.

Inputs to the agent are:

1) Current date and time.

2) $O_{T}(t), O_{T}(t-1), O_{T}(t-2), O_{T}(t-3), O_{T}(t-4)$. $O_{T}(t)$ is the current outdoor temperature. $O_{T}(t-x)$ is the outdoor temperature at the previous $x$ sample.

3) $I_{T}(t), I_{T}(t-1), I_{T}(t-2), I_{T}(t-3), I_{T}(t-4) ; I_{T}(t)$ is the current average zone temperature. $I_{T}(t-x)$ is the average zone temperature at the previous $x$ sample. Average zone temperature is calculated by averaging the measured temperature values of all rooms in the zone.

4) $W_{I}(t), W_{I}(t-1), W_{I}(t-2), W_{I}(t-3), W_{I}(t-4)$; $W_{I}(t)$ is the current input water temperature for the zone. $W_{i}(t-x)$ is the input water temperature for the zone at the previous $x$ sample.

(1) - (3) are the inputs indicating for energy demand. (4) is the input indicating the energy resource.

Outputs from the agent are:

1) mARTMAP1 - indicating the required hot water flow (flow rate) to the zone; either ' 0 ' for no hot water flow or ' 1 ' for full hot water flow (maximum flow rate) to the zone (as illustrated in Fig. 4).

2) mARTMAP2 - the "learned" desired temperature setting (for the zone).

The User Agent provides the output every fifteen minutes. The above information is forwarded to the Source Agent to indicate when to switch on/off the boilers in order to heat the hot water to a desirable temperature.

- Online Learning \& User Interface: The User Agent also has the capability to accept and adapt its functionalities to new users' input, so as to allow the occupants the ability to set their own desired temperature. When Learn $=1$, occupants forces the mARTMAP to learn of the new desired temperature setting by presenting the new desired temperature value(s). Learning stops when mARTMAP has learned of this new temperature setting (Learn switches from 1 to 0 , when the desired temperature presented by the mARTMAP equals to the occupants new desired temperature, and is equal to the room temperature).

3) Source Agent for Boiler Management: The Source Agent uses the information provided by the User Agents to provide for the best operation of the heat source (bioler). The Source Agent is incorporated with its own mARTMAPs that allows the agent to describe for its required functionalities.

The inputs to the agent are:

1) Current date and time.

2) $O_{T}(t), O_{T}(t-1), O_{T}(t-2), O_{T}(t-3), O_{T}(t-4)$; $O_{T}$ is the outdoor temperature.

\footnotetext{
${ }^{3}$ Given the inputs provided to mARTMAP2, mARTMAP2 predicts for the best desired temperature for the room.
}

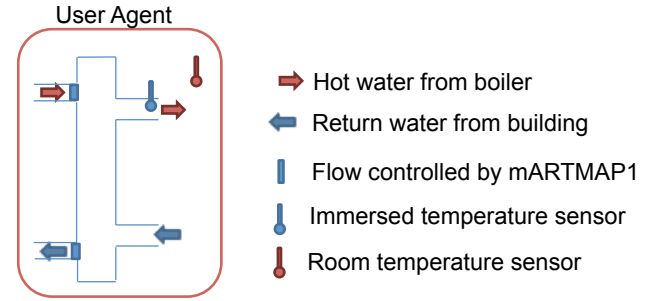

Fig. 4. User Agent responsible in providing for the thermal management for a zone in the building. If flow rate $=$ ' 1 ', hot water from the boiler is allowed to be distributed to the zone at the maximum flow rate; else (flow $={ }^{\prime} 0$ '), no hot water is flowing into the zone.

3) $I_{y}(t), I_{y}(t-1), I_{y}(t-2), I_{y}(t-3), I_{y}(t-4) ; I_{y}$ is the average zone $y$ temperature. Average zone $y$ temperature is calculated by averaging the measured temperature values of all rooms in the zone.

4) $W_{O}(t), W_{O}(t-1), W_{O}(t-2), W_{O}(t-3), W_{O}(t-4)$; $W_{O}$ is the return water temperature from the building.

5) $W_{I}(t), W_{I}(t-1), W_{I}(t-2), W_{I}(t-3), W_{I}(t-4)$; $W_{I}$ is the provided water temperature for the building

where, $(t)$ is the current sampled value. $(t-x)$ is the previous $x$ sampled value. (1) - (3) are the inputs indicating for energy demand. (4) - (5) are the inputs indicating the energy resource.

When Learn $=1$, users force the mARTMAP to learn of a new hot water temperature setting for the bioler. When Learn $=0$, users are happy with the heat provided. When Learn $=1$, users set the hot water temperature for the boiler. When Learn $=1$, temperature should be set to $\approx 80^{\circ} \mathrm{C}$ when high heat demand is required (for example, during the winter months), and less if there is lesser heat demand.

During the learning periods, the mARTMAP takes in the desired temperature setting from each User Agent and uses the provided information to learn of the building's heat demand.

The outputs are:

1) mARTMAP1 - ' 0 ' = boiler is switched off or ' 1 ' = boiler is switched on (as illustrated in Fig. 5).

2) mARTMAP2 - the "learned" ideal hot water temperature to be maintained (and bioled) by the bioler.

3) mARTMAP3 - The "learned" desired building temperature to be maintained.

Similar to the User Agents, the Source Agent provides its outputs at every fifteen minutes.

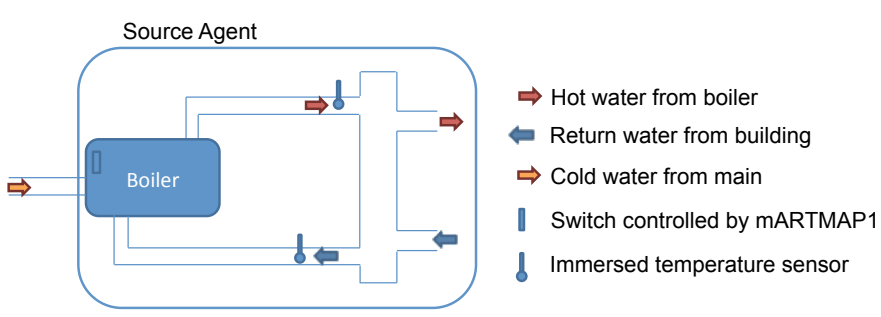

Fig. 5. Source Agent responsible for the bioler management.

\section{Results}

The desired space temperature required for thermal comfort management is $\approx 23^{\circ} \mathrm{C}$ during office hours (06:00-21:00 
Monday to Friday) and $\approx 10^{\circ} \mathrm{C}$ otherwise.

The existing rule-based BMS is compared to the mARTMAP-MAS IHMS against the following functions:

1) Building energy control - to provide better boiler management for the building.

2) Thermal comfort management - to maintain the desired space temperature.

Four sets of values are required for the comparison:

1) Actual temperature sensors and metering data.

2) Space temperature values produced by the simulated SLB model, utilising the model of the existing BMS (Sec. IV-A) and the use of the measured hot water temperature values flowing to the three zones ${ }^{4}$.

3) Temperature sensors and metering data produced by the simulated SLB model with the existing BMS and new boiler controls described in Sec. IV-B3.

4) Temperature sensors and metering data produced by the simulated SLB model with the mARTMAP-MAS IHMS.

Actual temperature sensors and metering data are taken from $5^{\text {th }}$ March 2012 to $25^{\text {th }}$ May 2012, omitting the data between $22^{\text {nd }}$ March 2012 09:00 to 24 ${ }^{\text {th }}$ March 2012 22:25 because no temperature (sensor) data were collected during these time.

Fig. 6 and 7 show that the SLB simulation model for zone BIU and Ground Floor are able to produce similar zone temperature values to that of the actual floor temperature sensor reading 5 . This is due to the similarity in the distribution of the temperature values produced by the SLB simulation model (box plot $^{6}$ label ' 2 ') and that of the actual sensor data (box plot label ' 1 ' in the two figures). The Simulink ${ }^{\circledR}$ SLB's building simulation model is therefore used to test the capabilities of the proposed mARTMAP-MAS IHMS.

Fig. 7 shows that the existing BMS cannot provide an efficient thermal comfort management for the Ground Floor. This has resulted in the inability for the BMS to meet with the required temperature setting of the floor.

Fig. 8 shows that the building simulation model for zone First Floor is unable to capture the non-linear dynamics of the thermal resistivity of this zone (box plot ' 2 ' in the figure is significantly different from box plot ' 1 '). Thermal resistivity has resulted in the slow heat loss from the zone to the outside air. The figure also shows that existing BMS (box plot ' 1 ') is unable to incorporate the thermal resistivity of this zone in its decision making process; whereby due to the slow heat loss, heat should only be provided later than the other zones. This has resulted in high number of times when the recorded temperature of the zone is higher than what is desired.

\section{A. Building Energy Control}

Table I and Fig. 9 show how much heat (hot water temperature) is provided by the Source Agent to help maintain the thermal comfort level of the building, in comparison to what was provided by the existing BMS. Table I and Fig. 9 show that less heat is required by the building in

\footnotetext{
${ }^{4}$ This is to simulate the use of the existing boiler controllers.

${ }^{5}$ The temperature sensor reading is within $\pm 1 \%$ of the actual temperature.

${ }^{6}$ More information on box plot can is described in [21] and Fig. 6
}

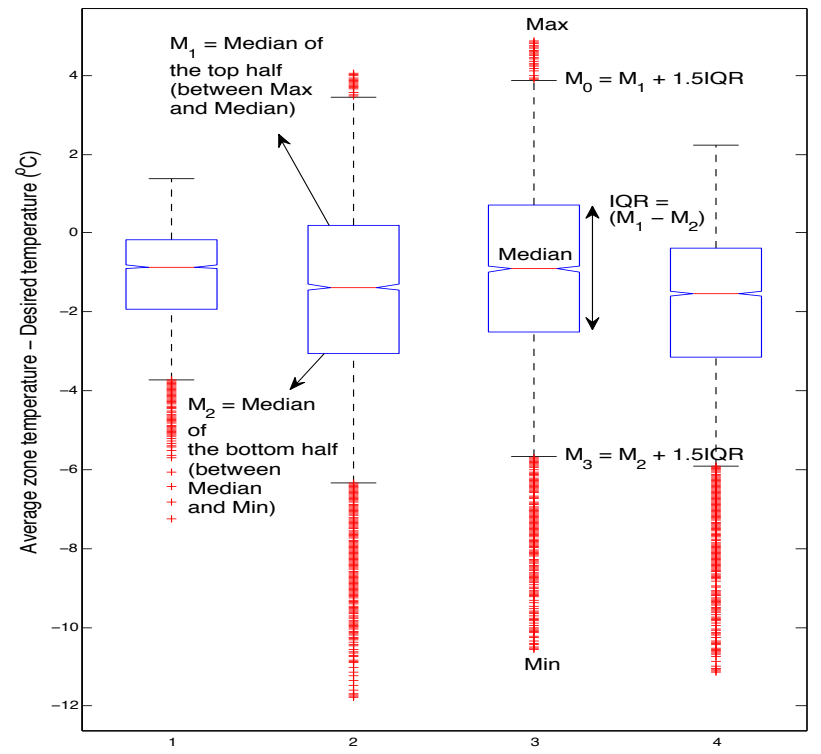

Fig. 6. Temperature distribution for BIU zone. The box plot illustrating the distribution of the temperature differences $\left(\right.$ in ${ }^{\circ} \mathrm{C}$ ) between the recorded average zone temperature and the desired zone temperature for the BIU zone, which are calculated between 06:00 to 21:00 with (1) data taken from the actual sensor values, (2) the simulated SLB model using the model of the existing BMS (as described in Sec. IV-A) and the measured hot water temperature values flowing to the zone, (3) the simulated SLB model using the model of the existing BMS and new boiler controls (as described in Sec. IV-B3), and (4) the simulated SLB model using the mARTMAP-MAS IHMS for thermal comfort management and boiler controls.

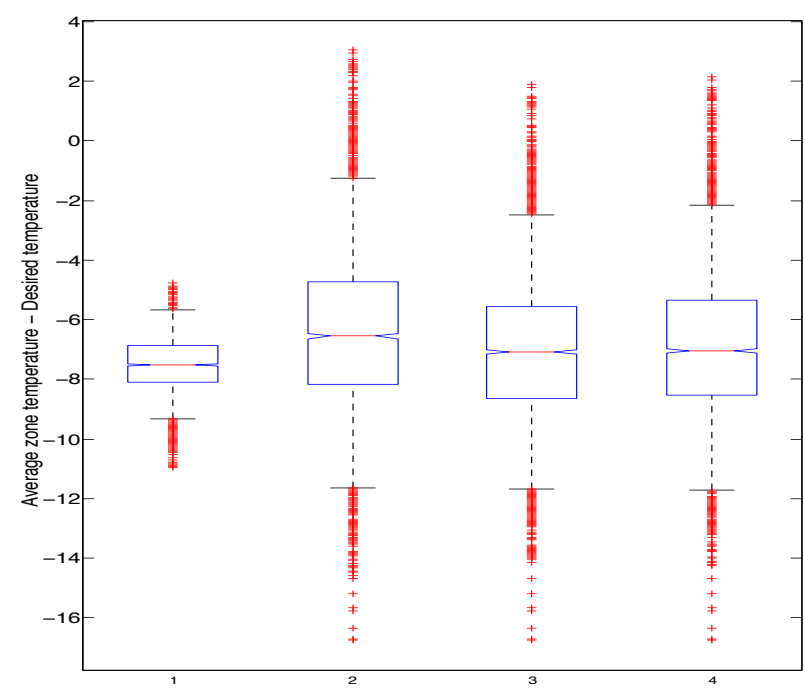

Fig. 7. Temperature distribution for Ground Floor zone. The box plot illustrating the distribution of the temperature differences between the recorded average zone temperature and the desired zone temperature for the Ground Floor zone, which are calculated between 06:00 to 21:00 with (1) data taken from the actual sensor values, (2) the simulated SLB model using the model of the existing BMS and the measured hot water temperature values, (3) the simulated SLB model using the model of the existing BMS and new boiler controls, and (4) the simulated SLB model using the mARTMAP-MAS IHMS for thermal comfort management and boiler controls.

order to maintain the desired space temperature. Therefore, by employing mARTMAP-MAS IHMS, large energy saving can be achieved. 


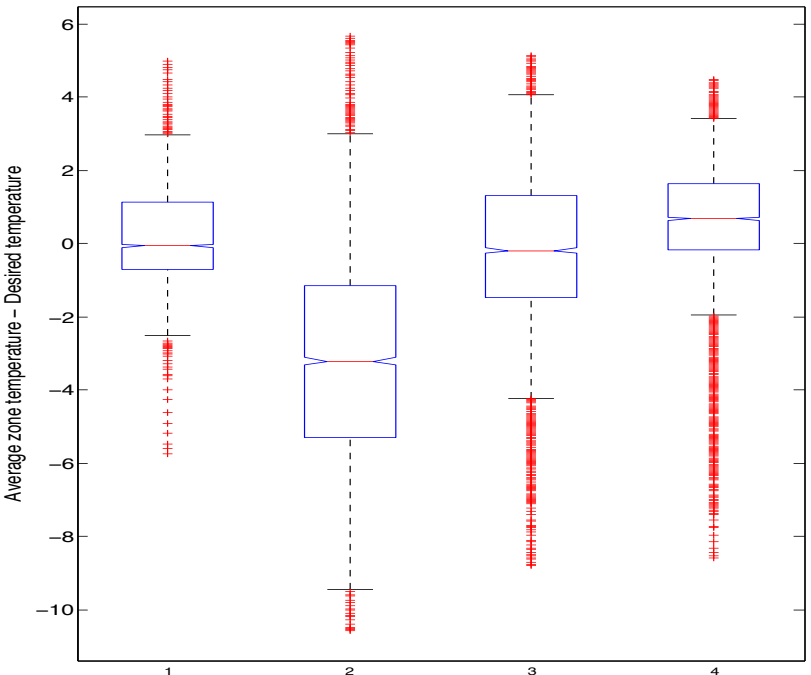

Fig. 8. Temperature distribution for First Floor zone. The box plot illustrating the distribution of the temperature differences $\left(\right.$ in ${ }^{\circ} C$ ) between the recorded average zone temperature and the desired zone temperature for First Floor zone, which are calculated between 06:00 to 21:00, with (1) data taken from the actual sensor values, (2) the simulated SLB model using the model of the existing BMS and the measured hot water temperature values flowing to the zone, (3) the simulated SLB model using the model of the existing BMS and new boiler controls, and (4) the simulated SLB model using the mARTMAPMAS IHMS for thermal comfort management and boiler controls.

TABLE I

COMPARING THE COST OF ENERGY USAGE BETWEEN THE EXISTING BMS AND THE MARTMAP-MAS IHMS

\begin{tabular}{l|c|c}
\hline & Energy used (MWh) & Cost $(£)$ \\
\hline Existing BMS & 55.0090 & 2007.00 \\
\hline $\begin{array}{l}\text { Simulation of the existing BMS } \\
\text { with new boiler controls }\end{array}$ & 27.0839 & 1132.70 \\
(sec. IV-B3) & & \\
\hline mARTMAP-MAS IHMS & & 1085.80 \\
\hline $\begin{array}{l}\text { mARTMAP-MAS IHMS saving against actual values } \\
\text { mARTMAP-MAS IHMS saving against simulated values }\end{array}$ & $\begin{array}{c}57.56 \% \\
4.14 \%\end{array}$ \\
\hline
\end{tabular}

${ }^{\text {a }}$ The energy used by the building between $1^{\text {st }}$ March to $25^{\text {st }}$ May 2012. Information is estimated based on the information provided by the energy provider e.on and the installed BMS.

b Box plot labelled ' 3 ' in the Fig. $6-8$.

c Box plot labelled ' 4 ' in the Fig. $6-8$.

\section{B. Thermal Comfort Management}

Fig. 6 - 8 and Table II show that the mARTMAP-MAS IHMS can provide better heat distribution control in comparison to the existing BMS. This is because there are (i) less positive temperature differences between the zone temperature and the desired temperature (Fig. 6 - 8) and (ii) smaller temperature differences (small standard deviation or Std. Dev) in comparison to the existing BMS (Table II). This is achieved because the mARTMAP-MAS IHMS is able to predict the heat demand of the zone. The predictive capability, along with the two-way interaction between the User Agents and the Source Agent, help ensure that the demand of heat is met most efficiently.

\section{SUMMARY \& CONCLUSION}

Results show that the mARTMAP-MAS IHMS can provide better heat distribution control in comparison to the existing
TABLE II

COMPARING THE EFFECTIVENESS BETWEEN THE TwO DESCRIBED Methods in Providing The Thermal Comfort Management.

\begin{tabular}{|c|c|c|c|}
\hline & \multirow[t]{2}{*}{ Zone ID } & \multicolumn{2}{|c|}{$\begin{array}{c}\text { Recorded - Desired) } \\
\text { Temperature }\left({ }^{\circ} C\right)\end{array}$} \\
\hline & & Mean & Std. Dev \\
\hline \multirow{3}{*}{$\begin{array}{l}\text { Ground } \\
\text { Floor } \\
\text { (GF) }\end{array}$} & Actual GF & -7.5251 & 1.0465 \\
\hline & $\begin{array}{l}\text { Simulated GF with } \\
\text { the existing BMS and } \\
\text { new boiler controls }\end{array}$ & -7.0487 & 2.5940 \\
\hline & $\begin{array}{l}\text { Simulated GF with } \\
\text { mARTMAP-MAS IHMS }\end{array}$ & -6.8768 & 2.6238 \\
\hline \multirow{3}{*}{$\mathrm{BIU}$} & Actual BIU & -1.2057 & 1.3174 \\
\hline & $\begin{array}{l}\text { Simulated BIU with } \\
\text { the existing BMS and } \\
\text { new boiler controls }\end{array}$ & -1.1501 & 2.5744 \\
\hline & $\begin{array}{l}\text { Simulated BIU with } \\
\text { mARTMAP-MAS IHMS }\end{array}$ & -2.0121 & 2.3142 \\
\hline \multirow{3}{*}{$\begin{array}{l}\text { First } \\
\text { Floor } \\
\text { (FF) }\end{array}$} & Actual FF & 1.5107 & 0.3282 \\
\hline & $\begin{array}{l}\text { Simulated FF with } \\
\text { the existing BMS and } \\
\text { new boiler controls }\end{array}$ & -0.1716 & 2.1528 \\
\hline & $\begin{array}{l}\text { Simulated FF with } \\
\text { mARTMAP-MAS IHMS }\end{array}$ & 1.9370 & 0.4665 \\
\hline
\end{tabular}

a The temperature differences are calculated only during the office hours (between the hours of 06:00 - 21:00)

b Box plot labelled ' 3 ' in the Fig. $6-8$.

' Box plot labelled ' 4 ' in the Fig. $6-8$

BMS. This is because the mARTMAP not only provides for the required heat distribution control and the new boiler controls, but also has the ability to predict the heat demand. This predictive capability, along with the appropriate and coordinated interaction between the User Agents and the Source Agent, help minimise any unnecessary heat waste or the residual heat resulted from high room/zone temperature at times of low heat demand.

This paper also proposes new improvements to the SLB's BMS so that efficient energy usage of the building and energy saving can be achieved.

\section{REFERENCES}

[1] A. I. Dounis, D. E. Manolakis. "Design of a fuzzy system for living space thermal comfort regulation", Applied Energy 2001, vol. 69, pp. 119-144, 2001.

[2] A.I. Dounis, C. Caraiscos, "Advanced control systems engineering for energy and comfort management in a building environment - A review". Renewable and Sustainable Energy Reviews, Vol. 13, Issues 6-7, pp. 12461261, 2009.

[3] M. Gouda, S. Danaher, C. Underwood, "Thermal comfort based fuzzy logic controller", Building Services Engineering Research and Technology 2001, vol. 22, no. 4, pp. 237-253, 2001.

[4] D. Kolokotsa, "Comparison of the performance of fuzzy controllers for the management of the indoor environment", Building and Environment, vol. 38, pp. 1439-1450, 2003.

[5] F. Calvino, M. L. Gennusca, G. Rizzo, G. Scaccianoce, "The control of indoor thermal comfort conditions: introducing a fuzzy adaptive controller", Energy and Buildings, vol. 36, pp. 97-102, 2004

[6] J. Liang and R. Du, "Thermal Comfort Control Based on Neural Network for HVAC Application", Proceedings of the 2005 IEEE Conference on Control Applications, Toronto, Canada, August, 2005.

[7] ASHRAE, 2005 ASHRAE Handbook: Fundamentals, 2005.

[8] ISO 7730 (International Standard), "Moderate thermal environments Determination of the PMV and PPD indices and specification of the conditions for thermal comfort", 1994.

[9] F. Yamada, K. Yonezawa, S. Sugarawa, N. Nishimura, "Development of air-conditioning control algorithm for building energy-saving," In IEEE International Conference on Control Applications, 1999. 

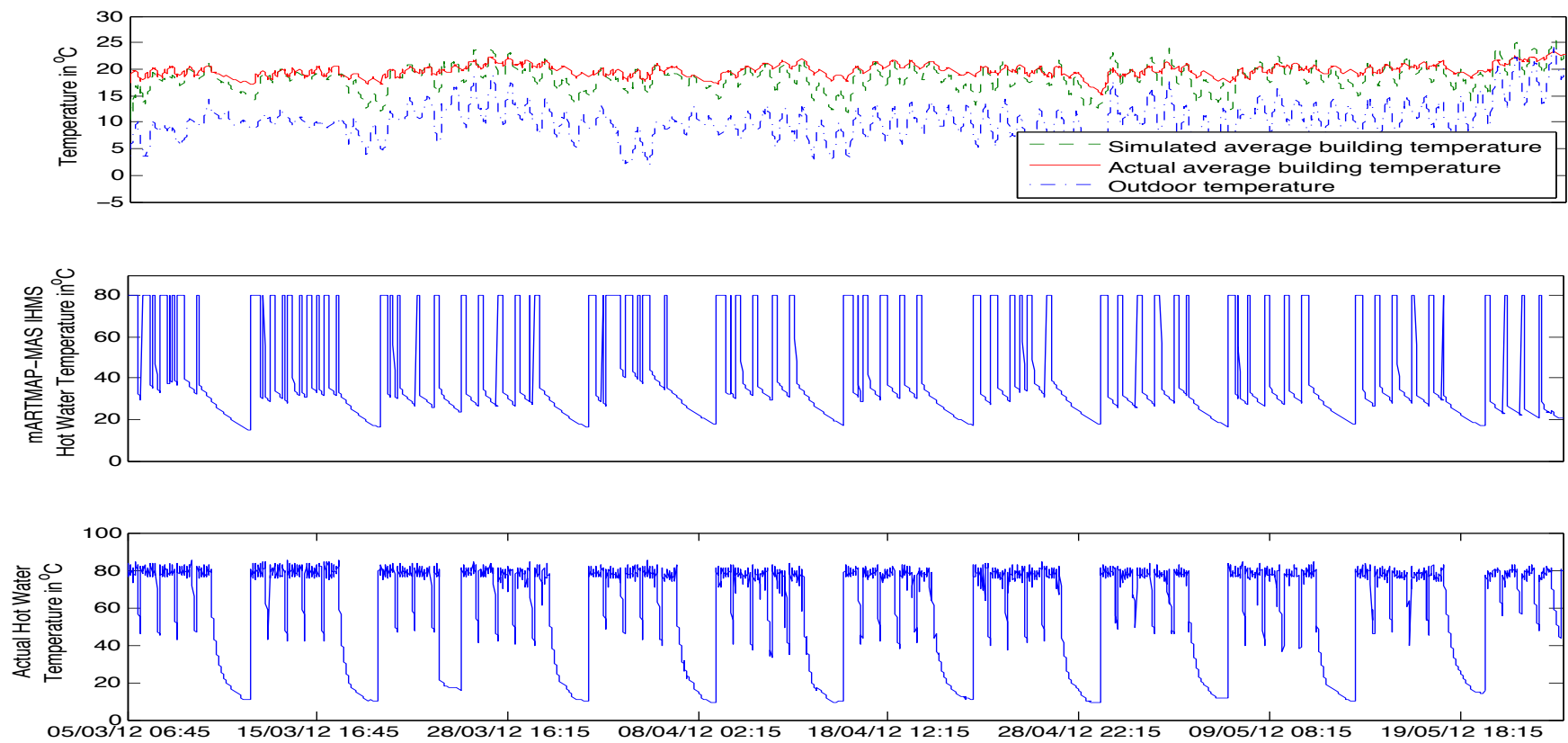

Fig. 9. The simulated and recorded hot water temperature (heat source) and the average building temperature of SLB. Figure shows that the mARTMAP-MAS IHMS is capable of maintaining towards the desired temperature of the building (efficient thermal comfort management) with less heat produced. Figure shows that the existing BMS has resulted in large amount of energy waste, whereby heat is produced (hot water) when not required (large difference between the temperature provided by mARTMAP-MAS IHMS and the actual hot water, despite the small temperature differences between the simulated and actual average building temperature).

[10] A. Garrett, "Fuzzy ART and Fuzzy ARTMAP Neural Networks," 2003, [Online] http://www.mathworks.com/matlabcentral/fileexchange/4306

[11] P. Davidsson and M. Boman, "Distributed Monitoring and Control of Office Buildings by Embedded Agents," Information Sciences, vol. 171, pp. 293-307, 2005.

[12] P. Davidsson and M. Boman, "Saving Energy and Providing Value Added Services in Intelligent Buildings: A MAS Approach," in Proceedings of the Second International Symposium on Agent Systems and Applications and Fourth International Symposium on Mobile Agents, 2000.

[13] M. Boman, P. Davidsson, and H. L. Younes, "Artificial Decision Making Under Uncertainty in Intelligent Buildings," in Proceedings of the Fifteenth Conference on Uncertainty in Artificial Intelligence, Stockholm, Sweden, pp. 65-70, 1999.

[14] B. Qiao, K. Liu, and C. G. Guy, "A multi-agent system for building control", In Proceedings of IEEE/WIC/ACM International Conference on Intelligent Agent Technology (IAT'06), Hong Kong, 2006.

[15] L. Tang, C. and Guy, "Energy saving in intelligent buildings - via energy harvesting in wireless sensor networks", In Euromedia 2008, J. Tavares, and R. N. Jorge (Eds.), Eurosis, Ghent, pp. 92-94, 2008.

[16] L. Zhang, G. Zhang, B. Shen, X. Xie, and Q. Yan, "Building Energy Saving Design Based on Multi-Agent System", in 2010 5th IEEE Conference on Industrial Electronics and Applications, pp. 840-844, 2010.

[17] G. Carpenter, S. Grossberg, N. Markuzon, J. Reynolds, and D. Rosen, "Fuzzy ARTMAP: A neural network architecture for incremental supervised learning of analog multidimensional maps," IEEE Trans. Neural Networks, vol. 3, no. 5, pp. 698-713, 1992.

[18] G. Carpenter, S. Grossberg, and J. Reynolds, "ARTMAP: Supervised real-time learning and classification of nonstationary data by a selforganizing neural network," Neural Network, vol. 4, pp. 565-588, 1991.

[19] X. Liu, I. Chilvers, M. Mokhtar, A. Bedford, K. Stitt and J. Yazdani, "Microgrid Development for Properties", in The 2nd European Conference on Innovative Smart Grid Technologies (ISGT- EUROPE 2011), 2011.

[20] Matlab, "Thermal Model of a House," [Online] Available: http://www.mathworks.co.uk/products/simulink/demos.html?file=/products /demos/shipping/simulink/sldemo_househeat.html

[21] D. L. Massart, J. Smeyers-Verbeke, X. Caprona, and K. Schlesier, "Visual Presentation of Data by Means of Box Plots", Practical Data Handling, LC-GC Europe, vol. 18, no. 4, pp. 215-218, 2005.
Maizura Mokhtar Maizura Mokhtar graduated in BEng (Hons) in Electronics and Computing from Nottingham Trent University, MSc in Control Systems from University of Sheffield and a $\mathrm{PhD}$ in Electronics from University of York. She has previously worked as a Research Associate in the Department of Electronics in the University of York. She is currently working as a Post Doctoral Research Assistant in the School of Computing, Engineering and Physical Sciences, University of Central Lancashire, researching in the integration of intelligence to (energy) systems.

Her research interests are artificial intelligence, bio-inspired controls and systems, intelligent systems.

Xiongwei Liu Xiongwei Liu received his BEng (Hons) degree from National University of Defence Technology, Changsha, in 1985, and his MSc (Distinction) and $\mathrm{PhD}$ degrees from Harbin Institute of Technology in 1988 and 1991 respectively. His employment experience included Northwestern Polytechnic University, Huaqiao University, Leeds Met University, University of Hertfordshire and University of Central Lancashire. His research interests include wind energy engineering, renewable energy technologies, smart grid and microgrid, and intelligent energy management system. He received a research fellowship from Alexander-von-Humboldt Foundation of Germany, which allowed him to visit Ruhr University Bochum, as a research fellow for 18 months from 1993. In 1999 he was awarded a Bronze Medal by Huo Yingdong Education Funding Council and a Model Worker Medal by the Mayor of Quanzhou, China, due to his excellent contributions in higher education when he served as a professor at Huaqiao University. He received a research fellowship from Chinese Scholarship Council, which allowed him to visit Technical University Berlin as a senior research fellow for 6 months in 2000 .

Xiongwei Liu has been working as Chair Professor of Energy and Power Management and Head of Wind Energy Engineering Research Group at the University of Central Lancashire since October 2010. From September 2012, he is working as Professor of Sustainable Engineering at the University of Cumbria. 